\title{
East Asian Monsoon Forcing And North Atlantic Subtropical High Modulation of Summer Great Plains Low-Level jet
}

\section{Kelsey Malloy ( $\sim$ kelsey.malloy@rsmas.miami.edu )}

University of Miami Rosenstiel School of Marine and Atmospheric Science https://orcid.org/00000002-1989-7490

\section{Ben P. Kirtman}

University of Miami Rosenstiel School of Marine and Atmospheric Science

\section{Research Article}

Keywords: teleconnections, divergence, anomalies, Atlantic, low-level jet

Posted Date: January 3rd, 2022

DOl: https://doi.org/10.21203/rs.3.rs-1153667/v1

License: (c) (i) This work is licensed under a Creative Commons Attribution 4.0 International License.

Read Full License 


\section{Abstract}

Dynamic influences on summertime seasonal United States rainfall variability are not well understood. A major cause of moisture transport is the Great Plains low-level jet (LLJ). Using observations and a dry atmospheric general circulation model, this study explored the distinct and combined impacts of two prominent atmospheric teleconnections - the East Asian monsoon (EAM) and North Atlantic subtropical high (NASH) - on the Great Plains LLJ in the summer. Separately, a strong EAM and strong western $\mathrm{NASH}$ are linked to a strengthened LLJ and positive rainfall anomalies in the Plains/Midwest. Overall, NASH variability is more important for considering the LLJ impacts, but strong EAM events amplify western NASH-related Great Plains LLJ strengthening and associated rainfall signals. This occurs when the EAM-forced Rossby wave pattern over North America constructively interferes with low-level wind field, providing upper-level support for the LLJ and increasing mid- to upper-level divergence.

\section{Introduction}

Continental United States (CONUS) summer rainfall variability remains an important field of research due to its implications for human health and the economy. Unfortunately, current subseasonal-to-seasonal forecasts for summer precipitation have relatively low skill (Becker et al. 2014; Hao et al. 2018; Jha et al. 2019; Malloy and Kirtman 2020; Slater et al. 2019), likely because there is little to no consensus about the dominant cause(s) of low-frequency precipitation variability. Compared to winter, the warm season presents unique challenges, such as lower signal-to-noise ratios from weaker subtropical jet streams, SST anomalies, tropical convection systems, and extratropical circulation (Dirmeyer et al. 2003; Gianotti et al. 2013; Lee et al. 2009; Malloy and Kirtman 2020; Schubert et al. 2002; Tian et al. 2017; Zhou et al. 2012).

The Great Plains low-level jet (LLJ) is a prominent circulation feature east of the Rocky Mountains, typically forming at nighttime just above the boundary layer between 925-850 hPa (Banta et al. 2001; Blackadar 1957; Fast and McCorcle 1990; Gimeno et al. 2016; Holton 1967; Jiang et al. 2007; Mitchell et al. 1995; Parish et al. 1988; Parish and Oolman 2010; Shapiro et al. 2016; Whiteman et al. 1997). Its fastmoving southerly winds act as a conveyor belt of heat and moisture to the Plains and Midwest, causing precipitation at the jet exit where low-level convergence occurs (Higgins et al. 1997; Hodges and Pu 2019; Pu and Dickinson 2014; Weaver et al. 2009a). Major pluvial events are linked to the strengthening of the Great Plains LLJ (Arritt et al. 1997; Cook et al. 2008; Feng et al. 2016) with low-level fluxes typically peaking in the mid-summer months (Weaver and Nigam 2008); Algarra et al. (2019) found that the Great Plains LLJ contributes up to $70-90 \%$ of the moisture transport into the Plains and up to $50 \%$ of the moisture transport into the Great Lakes and northeast U.S. regions in the summer.

There are numerous large-scale influences on Great Plains LLJ strength and variability. Teleconnections, such as the Pacific-North America (PNA) pattern, are found to have strong links to LLJ strengthening (Harding and Snyder 2015; Mallakpour and Villarini 2016; Malloy and Kirtman 2020; Nayak and Villarini 2017; Patricola et al. 2015; Weaver et al. 2016). Anomalous ridging over the northeast Pacific and anomalous troughing over western North America - characteristics of a negative PNA - promote 
strengthening of low-level southerlies and enhanced moisture transport over the Plains (Harding and Snyder 2015; Mallakpour and Villarini 2016; Malloy and Kirtman 2020; Nayak and Villarini 2017).

Many studies have analyzed additional trans-Pacific upper-level wave patterns and their connections to U.S. hydroclimate variability. The Asia-North America (ANA) teleconnection, an upper-level height pattern initiated by East Asian monsoon (EAM) heating, has been shown to link the climate variability over Asia and North America (Lau and Wang 2002; Lopez et al. 2019; Wang and Lau 2001; Zhao et al. 2018; Zhu and Li 2016; Zhu and Li 2018; Malloy and Kirtman 2021, submitted to Climate Dynamics). The EAM has been shown to produce an equivalent barotropic wave train response with or without ENSO in the background state (Lau and Wang 2002; Lopez et al. 2019; Trenberth and Guillemot 1996; Zhu and Li 2016; Zhu and Li 2018). Like the PNA, the ANA pattern is associated with an anomalous trough over western North America, promoting Great Plains LLJ strengthening. Zhu and Li (2018) found the ANA relationship to boreal summer rainfall variability has become stronger in recent decades, likely due to a northward shift of the monsoon system closer to the East Asian jet.

The North Atlantic Subtropical High (NASH) has a prominent control over large-scale circulation and the Great Plains LLJ. The NASH experiences its own variability, with its westward expansion or shift linked to Plains and/or southeast U.S. hydroclimate (Ferreira and Rickenbach 2020; Hodges and Pu 2019; Li et al. 2012; Pu et al. 2016; Ting and Wang 2006; Wei et al. 2019). Observational analysis and an associated GCM study suggested that Indian monsoon heating may result in increasing low-level easterly wind anomalies over the North Atlantic to shift the NASH westward (Kelly and Mapes 2011; Kelly and Mapes 2013). When the western ridge of the NASH intensifies, the Caribbean LLJ strengthens, increasing the easterly transport of moisture from the subtropical Atlantic and Caribbean Sea into the Gulf of Mexico (Ferreira and Rickenbach 2020; García-Martínez and Bollasina 2020; Krishnamurthy et al. 2015; MestasNuñez et al. 2007; Wang 2007). This additionally leads to increased southerlies in the Great Plains LLJ, enhancing the moisture fluxes into the Plains (Algarra et al. 2019; Hu et al. 2019; Parish and Oolman 2010). Ferreira and Rickenbach (2020) determined that western NASH events are associated with $40 \%$ greater Great Plains moisture transport compared to eastern NASH events. The NASH has shifted or extended west more frequently in recent decades. It is projected that trend will continue in a warming climate (Li et al. 2011; Li et al. 2012; Tang et al. 2017), though changes may be seasonally dependent and also controlled by poleward or equatorward shifts (Zhou et al. 2021). Nevertheless, understanding the impacts from these changes may yield knowledge beyond seasonal or interannual timescales.

Lastly, sea surface temperature (SST) anomalies in both the Pacific and Atlantic have been linked to the summer LLJ on monthly timescales. A warm tropical and northern Pacific and cool north Atlantic are associated with the strengthening of the Great Plains LLJ (Danco and Martin 2018; Hu and Feng 2012; Pegion and Kumar 2010; Ting and Wang 1997; Veres and Hu 2013; Weaver et al. 2009; Yu et al. 2017), though the extent to which this relationship is dynamically driven has been disputed. For example, there is a strong intraseasonal and interannual condition to the link between El Niño-Southern Oscillation (ENSO) and the Great Plains LLJ strengthening (Danco and Martin 2018; Krishnamurthy et al. 2015). Kam et al. (2014) and Malloy and Kirtman (2020) suggested that relying on tropical SST forecasts may 
limit skill in the summer. Atmospheric circulation variability (internal or forced) has been shown to exist in the absence of tropical forcing (Ding et al. 2011; Liu et al. 1998; Krishnamurthy et al. 2015; O'Reilly et al. 2018; Schubert et al. 2011; Zhao et al. 2018; Zhu and Li 2016) and may have a stronger link to Plains/Midwest hydroclimate (Burgman and Jang 2015; Ding et al. 2011; Malloy and Kirtman 2020; O'Reilly et al. 2018; Patricola et al. 2015; Schubert et al. 2002). In general, summer predictability beyond weather timescales has been related to the location and/or amplification of quasi-stationary Rossby waves (Ding and Wang 2005; Schubert et al. 2011; Mariotti et al. 2020; Beverley et al. 2019). Understanding the primary forcing mechanisms for these planetary waves, such as the EAM, and how they develop over North America with influence from the NASH circulation, is essential. Therefore, this study will concentrate on atmospheric teleconnections active in the June-July-August (JJA) season, particularly the EAM's and NASH's relationship with the Great Plains LLJ.

Despite the considerable literature on the EAM and NASH and their distinct influence on CONUS rainfall variability, there is little to no exploration into how these teleconnections interact. Because the Great Plains LLJ is a key driver of summer precipitation, this study will investigate the Great Plains LLJ response to the EAM forcing and consider how the NASH modulates that response. Simple dry atmospheric general circulation models (AGCMs) have been successful in reproducing the dynamics and variability of quasi-stationary/planetary wave activity from diabatic heating related to monsoons (Zhu and Li 2016; Zhu and Li 2018; Lopez et al. 2019; Malloy and Kirtman 2020, submitted to Climate Dynamics). We will use a simple dry nonlinear AGCM to understand the large-scale responses and modulation of the Great Plains LLJ on seasonal-to-interannual timescales. Section 2 will describe the datasets, details of the nonlinear AGCM and the experiments, and the relevant analysis methods. Section 3 will present the results as follows: The observed responses of the EAM and NASH and their interactions will be quantified. Then, this paper will examine the AGCM's EAM-forced response of the Great Plains LLJ. Finally, we will evaluate how NASH modulates the EAM-forced response. Section 4 will serve as a summary and reflection of the results in the context of previous literature and future work needed.

\section{Data And Methods}

\section{a. Observational dataset}

Pressure-level meridional wind, zonal wind, temperature, and geopotential height were taken from the European Centre for Medium-Range Weather Forecasts (ECMWF) fifth-generation reanalysis (ERA5). ERA5 atmospheric data is provided on a $0.25^{\circ}$ latitude/longitude grid (Hersbach et al. 2020). U.S. precipitation data were taken from the CPC Unified Gauge-based Analysis, provided on a $0.25^{\circ}$ latitude/longitude grid (Chen et al. 2008; Xie et al. 2007). This study used the June through August monthly data between 1979-2019 to serve as observations.

\section{b. Model and Experiments}

The model in this study is a dry, baroclinic, and nonlinear AGCM, i.e. it includes the full primitive equations of divergence, vorticity, temperature and surface pressure. It is a spectral model with 
Rhomboidal truncation at R42 - approximately $1.7^{\circ}$ latitude by $2.8^{\circ}$ longitude - with 26 vertical levels. The vertical levels are analogous to the Community Atmospheric Model, version 4 (CAM4), which uses hybrid sigma-pressure coordinate system. The AGCM is adapted from Brenner et al. (1984) to remove moist processes. Newtonian cooling is specified throughout the troposphere with enhanced damping near the surface. Rayleigh friction is specified at the lower levels and mimic realistic land-sea frictional contrasts to generate climatological features, such as the NASH, monsoonal systems, and the Great Plains LLJ. Realistic topography is also an important aspect of this model as the large-scale Great Plains LLJ requires topographical modulation of stationary flow (Byerle and Paegle 2003; Parish and Oolman 2010; Ting and Wang 2006; Weaver and Nigam 2011). Versions of this dry AGCM have been used in Kirtman et al. (2001) and is described in more detail in Malloy and Kirtman (2021), submitted to Climate Dynamics. This simple, idealized model is used for evaluating the large-scale teleconnections, primarily quasi-stationary wave activity and dry, dynamic processes.

The surface temperature climatology for JJA is input as background state for the model. This climatology was calculated from ERA5 data and interpolated to the model's grid. Each experiment was integrated forward for 900 days with the JJA background state to estimate the steady-state response for both seasonal and interannual analysis. Analysis excludes the first 100 days to assure that there is no contamination from the spin-up period.

This AGCM is used for both unforced and forced experiments. The unforced experiment, or control (hereby CTRL) run, is evaluated to compare climatology with observations. It is also compared to the EAM-forced runs to understand NASH modulation of the Great Plains LLJ, divergence, and circulation response in the model. The strong EAM experiment applies a constant diabatic heating via Gaussian bubble with a maximum of $2 \mathrm{~K} \mathrm{day}^{-1}$ centered at $30^{\circ} \mathrm{N}, 120^{\circ} \mathrm{E}$ and $300 \mathrm{hPa}$ (see Supp. Fig. 1 or Malloy and Kirtman 2021, submitted to Climate Dynamics), similar to Zhu and Li (2016) setup. The weak EAM experiment applies a forcing in the same location and of the same magnitude, but with the opposite sign i.e. there is negative diabatic heating (or cooling).

\section{c. Analysis Methods}

To investigate the separate and combined roles of the EAM and NASH in both observations and the AGCM, we calculated difference composites of 900-hPa meridional wind (V900) anomalies, 250-hPa geopotential height (Z250) anomalies, and rainfall anomalies. This means that anomalies are averaged for upper tercile events, and then subtracted from anomalies averaged from lower tercile events. We chose a composite analysis to highlight any nonlinearities in responses as weak and strong events may not yield equal and opposite LLJ anomalies. The EAM index is defined by $200-\mathrm{hPa}$ zonal wind (U200) circulation as described in Zhao et al. (2015): U200(2.5-10 $\left.\mathrm{N}, 105-140^{\circ} \mathrm{E}\right)-\mathrm{U} 200\left(17.5-22.5^{\circ} \mathrm{N}, 105-140^{\circ} \mathrm{E}\right)$ $+\mathrm{U} 200\left(30-37.5^{\circ} \mathrm{N}, 105-140^{\circ} \mathrm{E}\right)$, where $\mathrm{U} 200$ is averaged anomalies within the domain in the parentheses. The western NASH index is defined as follows: $Z 850\left(15-28^{\circ} \mathrm{N}, 50-85^{\circ} \mathrm{W}\right)$. A variation of this intensity index was used by Li et al. (2012) and Ferreira and Rickenbach (2020) in evaluating Z850 anomaly fields associated with the Great Plains LLJ strengthening, but this index highlights northern NASH variability, 
which impacts Plains/Midwest rainfall variability to a greater extent. Overall, the index distinguishes between strong western NASH events, with the western ridge over North America, and weak western $\mathrm{NASH}$ events, with the western ridge remaining over the Atlantic. All indices are standardized before anomalies are composited. We also composited the 1560 geopotential meter (1560-gpm) lines for observations corresponding to the strong and weak events to signify the NASH extent (Li et al. 2011) for the samples.

In addition, these composites are organized by a secondary condition, e.g. western NASH-related anomalies are further differentiated by strong (upper tercile) or weak (lower tercile) EAM events before averaging. To assess the significance of these difference composites, we performed a two-sided Wilcoxon rank-sum test. This test is preferred because it does not assume a Gaussian distribution, but it compares two samples' population mean ranks by considering if their distributions are the same.

To understand potential processes associated with these difference composites in observations and CTRL experiment, we included composites of $\mathrm{V}$ anomaly profiles at $30^{\circ} \mathrm{N}$, the latitude where the Great Plains LLJ and its related V900 anomalies are located. These composites separate by weak/strong western NASH and weak/strong EAM. This aids in visualizing the interactions in the vertical.

Finally, we assessed NASH's influence on the EAM-forced responses in the dry AGCM using difference of the composites, i.e. strong - weak EAM response during strong western NASH events minus strong weak EAM response during weak western NASH events. This determines whether the dry AGCM can simulate the correct tendency of the response by NASH modulation. Anomalies are calculated by subtracting the climatology from the CTRL experiment, and weak/strong western NASH events are based on the lower/upper quintile thresholds calculated from the CTRL experiment.

\section{Results}

\section{a. Observed Conditional Composite Analysis}

Figure 1 and Fig. 2 decompose the separate and combined influences of the EAM and NASH teleconnections in ERA5. The strong - weak western NASH difference composites in Figure 1 (top row) indicate that a western NASH is related to a $1-1.5 \mathrm{~m} \mathrm{~s}^{-1}$ strengthening of the Great Plains LLJ (top left) and up to $1 \mathrm{~mm}$ day $^{-1}$ rainfall anomalies over most of the eastern U.S. (top middle). The strong western NASH events (purple contour) correspond with a 1560-gpm line that extends far into the Gulf States, consistent with previous literature that connects west NASH extensions or shifts with amplified LLJrelated rainfall (Li et al. 2012). There is also an anomalous ridge-trough pattern oriented west-east over North America (top right).

When considering the strength of the EAM, the anomalous circulation and rainfall discussed above varies. Difference composites evaluated during weak EAM events (middle row) show a southward-shifted Great Plains LLJ that does not extend far into CONUS (middle left). Rainfall anomalies of $\sim 1.5-2 \mathrm{~mm}$ day $^{-1}$ are found over the Gulf States only, with dry anomalies over parts of the Plains/Midwest (middle). 
In contrast, during a strong EAM, the Great Plains LLJ strengthening is greater $\left(>2 \mathrm{~m} \mathrm{~s}^{-1}\right)$ and penetrates further into the U.S. (bottom left). This is related to more extreme wet anomalies $\left(>2 \mathrm{~mm} \mathrm{day}^{-1}\right)$ stretching from the Plains to the Northeast U.S. The NASH-related Z250 anomalies are different between weak and strong EAM events (middle, bottom left), particularly over East Asia, North America, and the North Atlantic. The north-south orientation of anomalous trough-ridge pattern over CONUS during strong EAM events signals a negative PNA and enhanced meridional transport (Harding and Snyder 2015; Malloy and Kirtman 2020).

We considered the reverse analysis as well by taking strong - weak EAM difference composites of V900 anomalies, further separated into weak or strong western NASH events (Fig. 2). A strengthened EAM is associated with a $\sim 0.5 \mathrm{~m} \mathrm{~s}^{-1}$ strengthening of the Great Plains LLJ (top left), though is further east from the Rockies than the climatological Great Plains LLJ location and the NASH-related LLJ strengthening. Rainfall anomalies are modest - up to $0.75 \mathrm{~mm} \mathrm{day}^{-1}$ - in the northern Plains and into Canada (top middle). An anomalous ridge is stretched over the North Pacific at around $30^{\circ} \mathrm{N}$ with an upper-level wave pattern emanating northward over East Asia (top right). In addition, there is a general southwest-northeast pattern of an anomalous trough-ridge over North America, and an anomalous trough off the coast of Northeast U.S.

Difference composites taken during weak western NASH events reveal $\sim 1.5 \mathrm{~m} \mathrm{~s}^{-1}$ weakening of the Great Plains LLJ (middle left) and $\sim 2 \mathrm{~mm} \mathrm{day}^{-1}$ dry anomalies over the Plains, Midwest, and Northeast U.S. (middle). During strong western NASH events, the Great Plains LLJ strengthening is weakly positive but not statistically significant (bottom left), and there are $\sim 1-1.5 \mathrm{~mm}$ day $^{-1}$ wet anomalies (bottom middle). The greatest differences in upper-level wave pattern are seen over the eastern North Pacific and North America, with opposite patterns depending on western NASH strength. This suggests that NASH exerts the primary influence over the Great Plains LLJ regardless of the EAM strength. In addition, because the anomalies are only statistically significant during weak western NASH events, EAM-related wave patterns may destructively interfere with strong western NASH-related wave patterns.

To further understand processes between the strong and weak events, Fig. 3 shows the vertical profile of $\mathrm{V}$ anomalies at $30^{\circ} \mathrm{N}$. Rows differentiate between NASH strength, and columns differentiate between EAM strength. The EAM-related flow can be discerned east of the Himalayas (100-120 $\mathrm{E})$ by the northerlies (left column) or southerlies (right column), which signals whether there is low-level divergence or convergence over the EAM region, respectively. The Great Plains LLJ is found between -100 and $-90^{\circ} \mathrm{W}$, with northerlies coinciding with a weak western NASH (top row) and southerlies coinciding with a strong western NASH (bottom row). During weak EAM and weak western NASH events (top left), as well as during strong EAM and strong western NASH events (bottom right), the LLJ-related winds are of the same sign as the upper-level flow. This suggests that when the EAM and western NASH are both weak or strong, their related circulation patterns are in constructive interference, i.e. the low- and upper-level flow are in alignment to promote enhanced precipitation patterns. While this mechanism is supported by 
previous literature (Harding and Snyder 2015; Mallakpour and Villarini 2016), we want to explore whether a simple dry AGCM can reproduce this interference between the EAM, NASH, and Great Plains LLJ.

\section{b. Control Experiment Climatology and Biases}

Before analyzing the dry AGCM responses, we evaluated the climatological biases of the model and its ability to produce realistic dynamic responses (e.g. quasi-stationary Rossby waves). Zonally-asymmetric components (represented by ${ }^{*}$ ) of time-mean circulation (represented by ${ }^{-}$) - also known as stationary waves - are useful for understanding the production and maintenance of Rossby waves. Seasonally, stationary waves describe preferred locations of meridional fluxes of heat and moisture, affecting hydroclimate. We compared the stationary waves in ERA5 and the CTRL experiment (no heating forcing) from the dry AGCM (Fig. 4). In observations, $Z \overline{2} 50^{\star}$ generally features high pressure over the continents and low pressures over the ocean basins in the mid-latitudes and subtropics at the edge of the East Asian or North Atlantic jet (top left). The CTRL experiment exhibits similar patterns (top middle) but with biases over the Pacific and Atlantic (top right). The bands of low pressure are higher in latitude over the Pacific, and the Atlantic is missing a band of low pressure at the subtropics. This has implications for the location of jet streams; the CTRL experiment $U 250$ bias (overlaid on top right) indicates a jet stream shifted northward. Overall, the model captures basic characteristics of upper-level circulation, but these biases are important for understanding the production of Rossby wave responses in the forcing experiments.

$Z 850$ * from observations presents high pressures over the ocean basins (bottom left), which coincides with the climatological location of subtropical highs (e.g. NASH). These ridges generally appear in the CTRL experiment (bottom middle), but the NASH is weaker and further north. These biases may have implications for discerning NASH influences, e.g. related anomalies that are higher in latitude than observations. Nevertheless, the basic circulation and Great Plains LLJ features follow NASH location and extent.

The Great Plains LLJ climatology can be compared in Fig. 5. The ERA5 time-mean V 900 shows a strong $\left(\sim 8 \mathrm{~m} \mathrm{~s}^{-1}\right)$ Great Plains LLJ feature (left). Despite the climatological core being about $5^{\circ}$ northward from observational estimates, the location in CTRL experiment is close to the Rockies. The magnitude of the climatological core is $3 \mathrm{~m} \mathrm{~s}^{-1}$, which is weaker than the observations. However, the objective of the study is to analyze large-scale dynamical differences between forced experiments, not to represent thermodynamics, diurnally-varying radiative processes nor mesoscale physics; therefore, this simulated Great Plains LLJ is within reason given that the model has relatively coarse resolution and lacks moist processes and associated land-atmosphere feedbacks.

\section{d. Strong - Weak EAM-forced Experiment Analysis}


An advantage of this experiment setup with the dry nonlinear AGCM is that one can assess the effect of sub-sampling 90-day (or one single season) means during the 900-day experiment. Fig. 6 demonstrates the internal variability of 90-day V900 means for this experiment; for V900 responses, the $\sigma$ values are relatively large on the northern and southern edges of the climatological Great Plains LLJ region, and substantial off both North American coasts. This suggests that fluctuations in V900 are primarily in the north-south direction. The Z250 and Z850 responses indicate relatively higher $\sigma$ values along the approximate climatological jet stream latitude and along the boundaries of climatological subtropical highs, respectively (Fig. 7). This likely means that fluctuations in upper and lower heights are linked to East Asian jet variations and shifts in the subtropical highs, respectively. By dividing the time-mean difference by this standard deviation, we assess the robustness (or statistical significance) of the longterm response on seasonal-to-interannual timescales.

The EAM-forced V900 response is summarized in Fig. 8, indicating a 0.5-1 $\mathrm{m} \mathrm{s}^{-1}$ strengthening - a 25\% magnitude increase compared to Fig. 5 (right) - in the Great Plains LLJ. This strengthening is confined to the northern side of the jet (right), which differs from the strong - weak EAM difference composite in Fig. 2 (top left). Overall, this forced response is considered robust on the seasonal timescale in the Great Plains and over the Gulf of Mexico, seen by the positive (negative) difference values that exceed $1 \sigma(-1 \sigma)$.

The EAM Z250 time-mean response shows zonally-oriented troughs and ridges that stretch from the EAM region and over the North Pacific (Fig. 9, left), with an anomalous trough-ridge pattern oriented west-east over North America, similar to the observed pattern (cf. Fig. 2, top right). The anomalous trough over western North America is typically associated with Great Plains LLJ strengthening (Harding and Snyder 2015; Mallakpour and Villarini 2016; Malloy and Kirtman 2020). The EAM Z850 time-mean response (right) presents anomalous ridging over eastern North America and the high-latitude North Atlantic and anomalous troughing over the mid-latitude Atlantic, which could signal an increased variability of the $\mathrm{NASH}$ in the west-east direction. The Z250 and Z850 responses are mostly robust except for the high latitudes and the eastern North Pacific/Alaska region.

To get a sense of the response in the vertical, we assessed the latitudinally averaged cross-section of strong - weak EAM V (left; meridional velocity) and divergence (right) response in the general region where the downstream wave response travels $\left(35-45^{\circ} \mathrm{N}\right.$; Fig. 10$)$. The response is mostly equivalent barotropic except for over Gulf of Alaska/eastern North Pacific. However, the most statistically significant $\Delta \mathrm{V}$ values are located over the EAM region as well as North America, including the upper-level trough and ridge from Fig. 9 (left). This corresponds to the anomalous divergence on the leeside of the Rockies (right). Despite the robust differences in this region, there is still substantial internal variability over the mid-latitude Pacific and/or the upper levels.

Lastly, we evaluated the influence of NASH on the EAM responses, visualized by taking the strong - weak EAM responses during strong western NASH events and subtracting by the strong - weak EAM responses during weak western NASH events (Fig. 11), done for both observations (top row) and the dry AGCM (bottom row). The climatological biases of the dry AGCM are apparent, with Great Plains LLJ 
strengthening $\sim 10^{\circ}$ northward from the observational strengthening (left column). However, by considering these biases and comparing the NASH-modulated strong - weak EAM response (shaded contours) with the original strong - weak EAM response (no NASH considered, solid black contours), it is evident that strong western NASH modulation is comparable between observations and the dry AGCM, i.e. a strong western NASH amplifies the Great Plains LLJ strengthening signal, especially on the side closest to the Rockies. The dry AGCM generally simulates enhanced 500-250-hPa layer-averaged divergence in the Plains associated with the enhanced precipitation anomalies from observations (middle column). This suggests that dry dynamics in the AGCM may be sufficient to produce basic NASH-related modulation of EAM-forced patterns, such that the tendencies are correct (see Supp. Fig. 2 for full strong weak EAM response separated by western NASH strength as in Fig. 2). Z250 patterns outside North America compare well to observations, but there are discrepancies in the dry AGCM representation of $\mathrm{NASH}$ modulation of Z250 over North America (right column) that may limit its representation.

NASH modulation is further demonstrated by taking vertical profiles of $\mathrm{V}$ where the Great Plains LLJ strengthening occurs $\left(30^{\circ} \mathrm{N}\right.$ for observations and $40^{\circ} \mathrm{N}$ for dry AGCM; Fig. 12). NASH modulation of circulation is notably similar to observations and the dry AGCM except over North Atlantic. Over the region of interest that affects the Great Plains LLJ, the dry AGCM presents alignment of positive $V$ values from the low to upper levels (bottom), though not as vertically stacked as presented in observations (top) or Fig. 3. Overall, the dry AGCM simulates NASH modulation of EAM-forced responses to a reasonable degree, including the amplification of Great Plains LLJ strengthening and related divergence during strong EAM and strong western NASH events.

\section{Summary And Discussion}

Seasonal forecasts of CONUS precipitation during the summer have relatively low skill, and there is little consensus on the driving causes of rainfall variability on this timescale. We suggested that examining large-scale Great Plains LLJ responses in a dry nonlinear AGCM will aid in discerning dynamic causes and variability of pluvial events. First, we compared observational analysis of the NASH and EAM teleconnections and their interactions. Then we analyzed and compared Great Plains LLJ responses from EAM experiments in a dry AGCM and explored whether NASH modulation of EAM circulation responses can be reproduced with simple dry dynamics.

Results from the ERA5 conditional difference composites (Fig. 1 and Fig. 2) suggested that the strength of the western NASH or EAM matters when considering Great Plains LLJ impacts. Strong western NASHrelated Great Plains LLJ strengthening and associated wet anomalies were greater during strong EAM events. However, EAM-related Great Plains LLJ responses were more dependent on the NASH location: during weak western NASH events, the strong - weak EAM response is a weakened Great Plains LLJ, and the LLJ response during strong western NASH events is not statistically significant. Profiles of $\mathrm{V}$ anomalies revealed that strong (weak) EAM and strong (weak) western NASH events were linked to inphase lower- and upper-level circulation patterns, providing enhanced upper-level support for the Great Plains LLJ (Fig. 3). 
The strong - weak EAM responses were largely captured by the dry AGCM, including an elongated wave structure over the North Pacific and anomalous trough over western North America (Fig. 9) comparable to observations (cf. Fig. 2, top right). This promoted robust Great Plains LLJ strengthening (Fig. 8). In addition, the dry AGCM simulated the amplification of the EAM-forced LLJ and mid- to upper-level divergence during a strong western NASH due to constructive interference of low- and upper-level wind patterns (Figs. 10 and 11), shedding light on the major dynamic causes of Great Plains LLJ strengthening and its impacts.

Despite the AGCM capturing many of the dynamical processes behind EAM responses and NASH modulation, there were climatological biases in the AGCM that help explain some of the discrepancies between observations and the model's EAM-NASH-LLJ relationships. For example, in the upper levels, the model had a northward-shifted jet stream due to increased horizontal height gradients further north (cf. Fig. 4). Accordingly, the AGCM's Great Plains LLJ climatological core (Fig. 5) and anomalies as well as the NASH were shifted northward. Our results complement previous research that found that the inaccurate location and strength of large-scale atmospheric features, such as the jet stream and subtropical high systems, can negatively impact long-range forecast skill (Liu et al. 2019; O'Reilly et al. 2018) or change the associated primary rainfall patterns (Zhou et al. 2021). Biases or discrepancies between the observations and AGCM could also be from processes not represented in the model, like SST variability, land-atmosphere feedbacks, or moisture processes. For example, NASH modulation of Z250 patterns over North America was not as well represented in the dry AGCM as the rest of the domain (cf. Figs. 10); this may indicate that NASH modulation over the continent should also simulate ENSO variability (Malloy and Kirtman 2021, submitted to Climate Dynamics) or soil moisture-circulation feedbacks (Dirmeyer et al. 2003; Koster et al. 2006; Jong et al. 2021).

Previous studies have suggested that monsoon forcing is related to the circumglobal teleconnection (CGT), a prominent mode of upper-level height variability in the summer (Ding and Wang 2005; Ding et al. 2011; Zhao et al. 2018). Typically, the CGT wavenumber-5 pattern is maintained by Indian monsoon heating, but Zhou et al. (2020) suggested the EAM influences the CGT. Additionally, Indian monsoon heating may relate to NASH shifts (Kelly and Mapes 2011; Kelly and Mapes 2013). While our results show similar features that relate the EAM to the CGT (Zhou et al. 2020), it is beyond the scope of this study to diagnose and disentangle true causal relationships between the EAM, NASH, Indian monsoon, and CGT. Future work will be needed to understand these inter-relationships and how they contribute to rainfall variability over Asia, North America, and Europe.

A future study should expand on NASH's role by forcing vorticity anomalies over the western NASH region with the AGCM or investigating other sources of North Atlantic Rossby wave activity (e.g. NAO; Weaver and Nigam 2008). In addition, the seasonal transition from early summer to late summer may also change the relationships between the NASH, EAM, and Great Plains LLJ. Simple AGCMs have the potential to isolate circulation responses from distinct forcing and evaluate the predictability of summer hydroclimate features. This research serves as a preliminary step for understanding more complex 
models and assessing the predictability of atmospheric dynamics in the summer on the more "elusive" long-range timescale.

\section{Declarations}

\section{Acknowledgements}

The authors acknowledge University of Miami Institute for Data Science and Computing (IDSC) for computational resources to complete many of the model experiments. This work was supported through NOAA Grants NA15OAR4320064, NA160AR4310141, N160AR4310149 and NA200AR430472 and DOE Grant DE-SC0019433.

Data Availability Statement

All data analyzed in this study are described in this article, including relevant citations for accessing the data. CPC Precipitation data provided by the NOAA/OAR/ESRL PSL, Boulder, Colorado, USA, at https://psl.noaa.gov/data/gridded/data.unified.daily.conus.html. The dry AGCM data are available upon reasonable request.

\section{References}

1. Algarra I, Eiras-Barca J, Miguez-Macho G, Nieto R, Gimeno L (2019) On the assessment of the moisture transport by the Great Plains low-level jet. Earth Sys Dyn Discuss 10:107-119. https://doi.org/10.5194/esd-10-107-2019

2. Banta R, Newsom RK, Lundquist JK, Pichugina YL, Coulter RL, Mahrt L (2002) Nocturnal Low-Level Jet Characteristics Over Kansas During Cases-99. Bound -Layer Meterol 105:221-252. https://doi.org/10.1023/A:1019992330866

3. Becker E, Dool Hvden, Zhang Q (2014) Predictability and Forecast Skill in NMME. J Climate 27:5891-5906. https://doi.org/10.1175/JCLI-D-13-00597.1

4. Beverley JD, Woolnough SJ, Baker LH, Johnson SJ, Weisheimer A (2019) The northern hemisphere circumglobal teleconnection in a seasonal forecast model and its relationship to European summer forecast skill. Clim Dyn 52(5):3759-3771. https://doi.org/10.1007/s00382-018-4371-4

5. Blackadar AK (1957) Boundary layer wind maxima and their significance for the growth of nocturnal inversions. Bull Amer Meteor Soc 38:283-290

6. Brenner S, Mitchell K (1984) (Kenneth Erwin)., Yang, C., U.S. Air Force Geophysics Laboratory. Atmospheric Sciences Division. The AFGL global spectral model: expanded resolution baseline version. Hanscom AFB, Massachusetts: Air Force Geophysics Laboratory, Air Force Systems Command, United States Air Force. (Retrieved from https://catalog.hathitrust.org/Record/102326036/Home) 
7. Burgman RJ, Jang Y (2015) Simulated U.S. Drought Response to Interannual and Decadal Pacific SST Variability. J Clim 28(12):4688-4705. https://doi.org/10.1175/JCLI-D-14-00247.1

8. Byerle LA, Paegle J (2003) Modulation of the Great Plains low-level jet and moisture transports by orography and largescale circulations. J Geophys Res 108:8611. https://doi.org/10.1029/2002JD003005

9. Chen M, Shi W, Xie P, Silva VBS, Kousky VE, Wayne Higgins R, Janowiak JE (2008) Assessing objective techniques for gauge-based analyses of global daily precipitation. J Geophys Res 113:D04110. https://doi.org/10.1029/2007JD009132

10. Cook KH, Vizy EK, Launer ZS, Patricola CM (2008) Springtime Intensification of the Great Plains LowLevel Jet and Midwest Precipitation in GCM Simulations of the Twenty-First Century. J Climate 21:6321-6340. https://doi.org/10.1175/2008JCLI2355.1

11. Danco JF, Martin ER (2018) Understanding the influence of ENSO on the Great Plains low-level jet in CMIP5 models. Clim Dyn 51:1537. https://doi.org/10.1007/s00382-017-3970-9

12. Ding Q, Wang B (2005) Circumglobal Teleconnection in the Northern Hemisphere Summer. J Climate 18:3483-3505. https://doi.org/10.1175/JCLI3473.1

13. Ding Q, Wang B, Wallace JM, Branstator G (2011) Tropical-Extratropical Teleconnections in Boreal Summer: Observed Interannual Variability. J Climate 24:1878-1896.

https://doi.org/10.1175/2011JCLI3621.1

14. Feng Z, Leung LR, Hagos S, Houze RA, Burleyson CD, Balaguru K (2016) More frequent intense and long-lived storms dominate the springtime trend in central US rainfall. Nat Commun 7:13429. https://doi.org/10.1038/ncomms13429

15. Ferreira RN, Rickenbach R, TM (2020) Effects of the North Atlantic Subtropical High on summertime precipitation organization in the southeast United States. Int J Climatol 40:5987-6001. https://doi.org/10.1002/joc.6561

16. García-Martínez IM, Bollasina MA (2020) Sub-monthly evolution of the Caribbean Low-Level Jet and its relationship with regional precipitation and atmospheric circulation. Clim Dyn 54(9):4423-4440. https://doi.org/10.1007/s00382-020-05237-y

17. Gianotti D, Anderson BT, Salvucci GD (2013) What Do Rain Gauges Tell Us about the Limits of Precipitation Predictability? J Climate 26:5682-5688. https://doi.org/10.1175/JCLI-D-12-00718.1

18. Gimeno L, Dominguez F, Nieto R, Trigo R, Drumond A, Reason CJC, Taschetto AS, Ramos AM, Kumar R, Marengo J (2016) Major Mechanisms of Atmospheric Moisture Transport and Their Role in Extreme Precipitation Events. Annu Rev Environ Resour 41:117-141. https://doi.org/10.1146/annurev-environ-110615-085558

19. Hao Z, Singh VP, Xia Y (2018) Seasonal drought prediction: Advances, challenges, and future prospects. Rev Geophys 56:108-141. https://doi.org/10.1002/2016RG000549

20. Harding KJ, Snyder PK (2015) The Relationship between the Pacific-North American Teleconnection Pattern, the Great Plains Low-Level Jet, and North Central U.S. Heavy Rainfall Events. J Climate 28:6729-6742. https://doi.org/10.1175/JCLI-D-14-00657.1 
21. Hersbach H, Bell B, Berrisford P, Hirahara S, Horányi A, Muñoz-Sabater J, Thépaut JN (2020) The ERA5 global reanalysis. Q J R Meteorol Soc 146(730):1999-2049. https://doi.org/10.1002/qj.3803

22. Hodges D, Pu Z (2019) Characteristics and variations of low-level jets in the contrasting warm season precipitation extremes of 2006 and 2007 over the Southern Great Plains. Theor Appl Climatol 136:753-771. https://doi.org/10.1007/s00704-018-2492-7

23. Holton JR (1967) The diurnal boundary layer wind oscillation above sloping terrain. Tellus, 19A, 199-205, https://doi.org/10.1111/j.2153-3490.1967.tb01473.x

24. Hu Q, Feng S, Oglesby RJ (2011) Variations in North American Summer Precipitation Driven by the Atlantic Multidecadal Oscillation. J Climate 24:5555-5570.

https://doi.org/10.1175/2011JCLI4060.1

25. Hu Q, Feng S (2012) AMO- and ENSO-Driven Summertime Circulation and Precipitation Variations in North America. J Climate 25:6477-6495. https://doi.org/10.1175/JCLI-D-11-00520.1

26. Jha B, Kumar A, Hu ZZ (2019) An update on the estimate of predictability of seasonal mean atmospheric variability using North American Multi-Model Ensemble. Clim Dyn 53(12):7397-7409. https://doi.org/10.1007/s00382-016-3217-1

27. Jiang X, Lau N, Held IM, Ploshay JJ (2007) Mechanisms of the Great Plains Low-Level Jet as Simulated in an AGCM. J Atmos Sci 64:532-547. https://doi.org/10.1175/JAS3847.1

28. Jong B, Ting M, Seager R (2021) Assessing ENSO Summer Teleconnections, Impacts, and Predictability in North America. J Clim 34(9):3629-3643. https://doi.org/10.1175/JCLI-D-20-0761.1

29. Kam J, Sheffield J, Yuan X, Wood EF (2014) Did a skillful prediction of sea surface temperatures help or hinder forecasting of the 2012 Midwestern US drought? Environ Res Lett 9:9.

https://doi.org/10.1088/1748-9326/9/3/034005

30. Kelly P, Mapes B (2011) Zonal mean wind, the Indian monsoon, and July drying in the western Atlantic subtropics. Journal of Geophysical Research: Atmospheres,

116(D21) https://doi.org/10.1029/2010JD015405

31. Kelly, P. and B. Mapes. (2013). Asian Monsoon Forcing of Subtropical Easterlies in the Community Atmosphere Model: Summer Climate Implications for the Western Atlantic. J. Climate, 26, 27412755, https://doi.org/10.1175/JCLI-D-12-00339.1.

32. Kelly, P. and B. Mapes. (2013). Asian Monsoon Forcing of Subtropical Easterlies in the Community Atmosphere Model: Summer Climate Implications for the Western Atlantic. J. Climate, 26, 27412755, https://doi.org/10.1175/JCLI-D-12-00339.1.

33. Krishnamurthy L, Vecchi GA, Msadek R, Wittenberg A, Delworth TL, Zeng F (2015) The Seasonality of the Great Plains Low-Level Jet and ENSO Relationship. J Climate 28:4525-4544. https://doi.org/10.1175/JCLI-D-14-00590.1

34. Koster RD, Sud YC, Guo Z, Dirmeyer PA, Bonan G, Oleson KW, Xue Y (2006) GLACE: the global landatmosphere coupling experiment. Part I: overview. J Hydrometeorol 7(4):590-610. https://doi.org/10.1175/JHM510.1 
35. Kushnir Y, Seager R, Ting M, Naik N, Nakamura J (2010) Mechanisms of Tropical Atlantic SST Influence on North American Precipitation Variability. J Climate 23:5610-5628. https://doi.org/10.1175/2010JCLI3172.1

36. Lau W, Weng H (2002) Recurrent Teleconnection Patterns Linking Summertime Precipitation Variability over East Asia and North America. J Meteorol Soc Jpn 80:1309-1324. https://doi.org/10.2151/jmsj.80.1309

37. Lee S, Wang C, Mapes BE (2009) A Simple Atmospheric Model of the Local and Teleconnection Responses to Tropical Heating Anomalies. J Climate 22(2):272-284. https://doi.org/10.1175/2008JCLI2303.1

38. Li W, Li L, Fu R, Deng Y, Wang H (2011) Changes to the North Atlantic Subtropical High and Its Role in the Intensification of Summer Rainfall Variability in the Southeastern United States. J Climate 24(5):1499-1506. https://doi.org/10.1175/2010JCLI3829.1

39. Li L, Li W, Kushnir Y (2012) Variation of the North Atlantic subtropical high western ridge and its implication to Southeastern US summer precipitation. Clim Dyn 39(6):1401-1412. https://doi.org/10.1007/s00382-011-1214-y

40. Liu Y, Ke Z, Ding Y (2019) Predictability of East Asian summer monsoon in seasonal climate forecast models. Int J Climatol 39(15):5688-5701. https://doi.org/10.1002/joc.6180

41. Lopez H, Lee S-K, Dong S, Goni G, Kirtman B, Atlas R, Kumar A (2019) East Asian Monsoon as a modulator of U.S. Great Plains heatwaves. Journal of Geophysical Research: Atmospheres 124:6342-6358. https://doi.org/10.1029/2018JD030151

42. Mallakpour I, Villarini G (2016) Investigating the relationship between the frequency of flooding over the central United States and large-scale climate. Adv Water Resour 92:159-171. https://doi.org/10.1016/j.advwatres.2016.04.008

43. Mariotti A, Baggett C, Barnes EA, Becker E, Butler A, Collins DC, Dirmeyer PA, Ferranti L, Johnson NC, Jones J, Kirtman BP, Lang AL, Molod A, Newman M, Robertson AW, Schubert S, Waliser DE, Albers J (2020) Windows of Opportunity for Skillful Forecasts Subseasonal to Seasonal and Beyond. Bull Am Meteorol Soc 101(5):E608-E625. https://doi.org/10.1175/BAMS-D-18-0326.1

44. Malloy KM, Kirtman BP (2020) Predictability of Midsummer Great Plains Low-Level Jet and Associated Precipitation. Weather Forecast 35(1):215-235. https://doi.org/10.1175/WAF-D-190103.1

45. Malloy KM, Kirtman BP (2021) The Summer Asia-North America Teleconnection and its Modulation by ENSO in Community Atmosphere Model, Version 5 (CAM5), Climate Dynamics, in review, 10.21203/rs.3.rs-1062059/v1

46. Mestas-Nuñez AM, Enfield DB, Zhang C (2007) Water Vapor Fluxes over the Intra-Americas Sea: Seasonal and Interannual Variability and Associations with Rainfall. J Climate 20(9):1910-1922. https://doi.org/10.1175/JCLI4096.1

47. Nayak MA, Villarini G (2017) A long-term perspective of the hydroclimatological impacts of atmospheric rivers over the central United States. Water Resour Res 53(2):1144-1166. 
https://doi.org/10.1002/2016WR019033

48. O'Reilly CH, Woollings T, Zanna L, Weisheimer A (2018) The Impact of Tropical Precipitation on Summertime Euro-Atlantic Circulation via a Circumglobal Wave Train. J Climate 31:6481-6504. https://doi.org/10.1175/JCLI-D-17-0451.1

49. Parish TR, Oolman LD (2010) On the Role of Sloping Terrain in the Forcing of the Great Plains LowLevel Jet. J Atmos Sci 67:2690-2699. https://doi.org/10.1175/2010JAS3368.1

50. Patricola CM, Chang P, Saravanan R (2015) Impact of Atlantic SST and high frequency atmospheric variability on the 1993 and 2008 Midwest floods: Regional climate model simulations of extreme climate events. Clim Change 129:397-411. https://doi.org/10.1007/s10584-013-0886-1

51. Pegion PJ, Kumar A (2010) Multimodel Estimates of Atmospheric Response to Modes of SST Variability and Implications for Droughts. J Climate 23:4327-4341.

https://doi.org/10.1175/2010JCLI3295.1

52. Pu B, Dickinson RE (2014) Diurnal Spatial Variability of Great Plains Summer Precipitation Related to the Dynamics of the Low-Level Jet. J Atmos Sci 71:1807-1817. https://doi.org/10.1175/JAS-D-130243.1

53. Pu B, Dickinson RE, Fu R (2016) Dynamical connection between Great Plains low-level winds and variability of central Gulf States precipitation. J Geophys Res Atmos 121:3421-3434. https://doi.org/10.1002/2015JD024045

54. Schubert S, Wang H, Suarez M (2011) Warm Season Subseasonal Variability and Climate Extremes in the Northern Hemisphere: The Role of Stationary Rossby Waves. J Climate 24:4773-4792. https://doi.org/10.1175/JCLI-D-10-05035.1

55. Shapiro A, Fedorovich E, Rahimi S (2016) A Unified Theory for the Great Plains Nocturnal Low-Level Jet. J Atmos Sci 73:3037-3057. https://doi.org/10.1175/JAS-D-15-0307.1

56. Slater L, Villarini G, Bradley A (2019) Evaluation of the skill of North-American Multi-Model Ensemble (NMME) Global Climate Models in predicting average and extreme precipitation and temperature over the continental USA. Clim Dyn 53:7381-7396. https://doi.org/10.1007/s00382-016-3286-1

57. Tang Y, Winkler J, Zhong S, Bian X, Doubler D, Yu L, Walters C (2017) Future changes in the climatology of the Great Plains low-level jet derived from fine resolution multi-model simulations. Sci Rep 7(1):1-10. https://doi.org/10.1038/s41598-017-05135-0

58. Ting $M$, Wang $H$ (2006) The Role of the North American Topography on the Maintenance of the Great Plains Summer Low-Level Jet. J Atmos Sci 63:1056-1068. https://doi.org/10.1175/JAS3664.1

59. Trenberth KE, Branstator GW, Karoly D, Kumar A, Lau NC, Ropelewski C (1998) Progress during TOGA in understanding and modeling global teleconnections associated with tropical sea surface temperatures. Journal of Geophysical Research: Oceans 103(C7):14291-14324. https://doi.org/10.1029/97JC01444

60. Veres MC, Hu Q (2013) AMO-Forced Regional Processes Affecting Summertime Precipitation Variations in the Central United States. J Climate 26:276-290. https://doi.org/10.1175/JCLI-D-1100670.1 
61. Wang C (2007) Variability of the Caribbean Low-Level Jet and its relations to climate. Clim Dyn 29:411. https://doi.org/10.1007/s00382-007-0243-z

62. Wang B, Wu Z, Li J, Liu J, Chang CP, Ding Y, Wu G (2008) How to measure the strength of the East Asian summer monsoon. J Climate 21(17):4449-4463. https://doi.org/10.1175/2008JCLI2183.1

63. Weaver SJ, Nigam S (2008) Variability of the Great Plains Low-Level Jet: Large-Scale Circulation Context and Hydroclimate Impacts. J Climate 21:1532-1551. https://doi.org/10.1175/2007JCLI1586.1

64. Weaver SJ, Schubert S, Wang H (2009) Warm Season Variations in the Low-Level Circulation and Precipitation over the Central United States in Observations, AMIP Simulations, and Idealized SST Experiments. J Climate 22:5401-5420. https://doi.org/10.1175/2009JCLI2984.1

65. Weaver SJ, Nigam S (2011) Recurrent supersynoptic evolution of the Great Plains low-level jet. J Clim 24(2):575-582. https://doi.org/10.1175/2010JCLI3445.1

66. Weaver SJ, Baxter S, Harnos K (2016) Regional Changes in the Interannual Variability of U.S. Warm Season Precipitation. J Climate 29:5157-5173. https://doi.org/10.1175/JCLI-D-14-00803.1

67. Wei W, Li W, Deng Y, Yang S (2019) Intraseasonal variation of the summer rainfall over the Southeastern United States. Clim Dyn 53(1):1171-1183. https://doi.org/10.1007/s00382-018-43456

68. Xie P, Chen M, Yang S, Yatagai A, Hayasaka T, Fukushima Y, Liu C (2007) A gauge-based analysis of daily precipitation over East Asia. J Hydrometeor 8:607-626. https://doi.org/10.1175/JHM583.1

69. Yu L, Zhong S, Winkler JA, Doubler DL, Bian X, Walters CK (2017) The inter-annual variability of southerly low-level jets in North America. Int J Climatol 37:343-357.

https://doi.org/10.1002/joc.4708

70. Zhao S, Deng Y, Black RX (2018) An Intraseasonal Mode of Atmospheric Variability Relevant to the U.S. Hydroclimate in Boreal Summer: Dynamic Origin and East Asia Connection. J Climate 31:98559868. https://doi.org/10.1175/JCLI-D-18-0206.1

71. Zhao G, Huang G, Wu R, Tao W, Gong H, Qu X, Hu K (2015) A New Upper-Level Circulation Index for the East Asian Summer Monsoon Variability. J Clim 28(24):9977-9996. https://doi.org/10.1175/JCLI-D-15-0272.1

72. Zhou F, Zhang R, Han J (2020) Influences of the East Asian Summer Rainfall on Circumglobal Teleconnection. J Climate 33(12):5213-5221. https://doi.org/10.1175/JCLI-D-19-0325.1

73. Zhou W, Leung LR, Song F, Lu J (2021) Future changes in the Great Plains low-level jet governed by seasonally dependent pattern changes in the North Atlantic subtropical high. Geophys Res Lett 48. https://doi.org/10.1029/2020GL090356

74. Zhu Z, Li T (2016) A New Paradigm for Continental U.S. Summer Rainfall Variability: Asia-North America Teleconnection. J Climate 29:7313-7327. https://doi.org/10.1175/JCLI-D-16-0137.1

75. Zhu Z, Li T (2018) Amplified contiguous United States summer rainfall variability induced by East Asian monsoon interdecadal change. Clim Dyn 50:3523. https://doi.org/10.1007/s00382-017-3821-8 
76. Weaver, S.J., S. Schubert, and H. Wang. (2009). Warm Season Variations in the Low-Level Circulation and Precipitation over the Central United States in Observations, AMIP Simulations, and Idealized SST Experiments. J. Climate, 22, 5401-5420, https://doi.org/10.1175/2009JCLI2984.1.

77. Weaver, S. J., \& Nigam, S. (2011). Recurrent supersynoptic evolution of the Great Plains low-level jet. Journal of Climate, 24(2), 575-582, https://doi.org/10.1175/2010JCLI3445.1.

78. Weaver, S.J., S. Baxter, and K. Harnos. (2016). Regional Changes in the Interannual Variability of U.S. Warm Season Precipitation. J. Climate, 29, 5157-5173, https://doi.org/10.1175/JCLI-D-14-00803.1.

79. Wei, W., Li, W., Deng, Y., \& Yang, S. (2019). Intraseasonal variation of the summer rainfall over the Southeastern United States. Clim Dyn, 53(1), 1171-1183, https://doi.org/10.1007/s00382-018-43456.

80. Whiteman, C.D., X. Bian, and S. Zhong. (1997). Low-Level Jet Climatology from Enhanced Rawinsonde Observations at a Site in the Southern Great Plains. J. Appl. Meteor., 36, 1363-1376, https://doi.org/10.1175/1520-0450(1997)036<1363:LLJCFE>2.0.C0;2.

81. Xie, P., M. Chen, S. Yang, A. Yatagai, T. Hayasaka, Y. Fukushima, and C. Liu, 2007: A gauge-based analysis of daily precipitation over East Asia. J. Hydrometeor., 8, 607-626, https://doi.org/10.1175/JHM583.1.

82. Yu, L., S. Zhong, J.A. Winkler, D.L. Doubler, X. Bian, and C.K. Walters. (2017). The inter-annual variability of southerly low-level jets in North America. Int. J. Climatol., 37, 343-357, https://doi.org/10.1002/joc.4708.

83. Zhao, S., Y. Deng, and R.X. Black. (2018). An Intraseasonal Mode of Atmospheric Variability Relevant to the U.S. Hydroclimate in Boreal Summer: Dynamic Origin and East Asia Connection. J. Climate, 31, 9855-9868, https://doi.org/10.1175/JCLI-D-18-0206.1.

84. Zhao, G., Huang, G., Wu, R., Tao, W., Gong, H., Qu, X., \& Hu, K. (2015). A New Upper-Level Circulation Index for the East Asian Summer Monsoon Variability, Journal of Climate, 28(24), 9977-9996, https://doi.org/10.1175/JCLI-D-15-0272.1.

85. Zhou, F., Zhang, R., \& Han, J. (2020). Influences of the East Asian Summer Rainfall on Circumglobal Teleconnection, J. Climate, 33(12), 5213-5221, https://doi.org/10.1175/JCLI-D-19-0325.1.

86. Zhou, W., Leung, L. R., Song, F., \& Lu, J. (2021). Future changes in the Great Plains low-level jet governed by seasonally dependent pattern changes in the North Atlantic subtropical high. Geophysical Research Letters, 48, https://doi.org/10.1029/2020GL090356.

87. Zhu, Z. and T. Li. (2016). A New Paradigm for Continental U.S. Summer Rainfall Variability: AsiaNorth America Teleconnection. J. Climate, 29, 7313-7327, https://doi.org/10.1175/JCLI-D-160137.1.

88. Zhu, Z. and T. Li. (2018). Amplified contiguous United States summer rainfall variability induced by East Asian monsoon interdecadal change. Clim Dyn, 50, 3523. https://doi.org/10.1007/s00382-0173821-8.

\section{Figures}




\section{Figure 1}

ERA5 strong - weak western NASH difference composites (top row) with no EAM condition considered, (middle row) only during weak EAM events, and (bottom row) only during strong EAM events. Difference composites of (left) V900 anomalies, (middle) CPC gauge-based precipitation anomalies, and (right) Z250 anomalies, with purple and green contours denoting the 1560-gpm line for strong and weak composites, respectively. Sample sizes for the composites and the percentage of total events the samples represent are annotated on top left of each row. Stippling indicates anomalies significant at $90 \%$ confidence level based on the Wilcoxin rank-sum test.

\section{Figure 2}

Similar format as Fig. 1, but ERA5 strong - weak EAM difference composites (top row) with no NASH condition considered, (middle row) only during weak western NASH events, and (bottom row) only during strong western NASH events.

\section{Figure 3}

ERA5 composites of $\mathrm{V}$ anomaly vertical profiles taken at $30^{\circ} \mathrm{N}$ during (top left) weak western NASH and weak EAM events, (top right) weak western NASH and strong EAM events, (bottom left) strong western $\mathrm{NASH}$ and weak EAM events, and (bottom right) strong western NASH and strong EAM events. Each panel annotates the approximate location of EAM-related flow and the Great Plains LLJ, and a thin vertical dotted line from LLJ is displayed to visualize upper-level support (or lack thereof).

\section{Figure 4}

(top row) Zonally-asymmetric component of the Z250 climatology for (left) ERA5, (middle) CTRL experiment, and (right) the subtraction difference between CTRL experiment and ERA5, with the U250 climatological bias overlaid (black contours). (bottom row) Same as top row, but for Z850. 


\section{V900 climatology}

ERA5

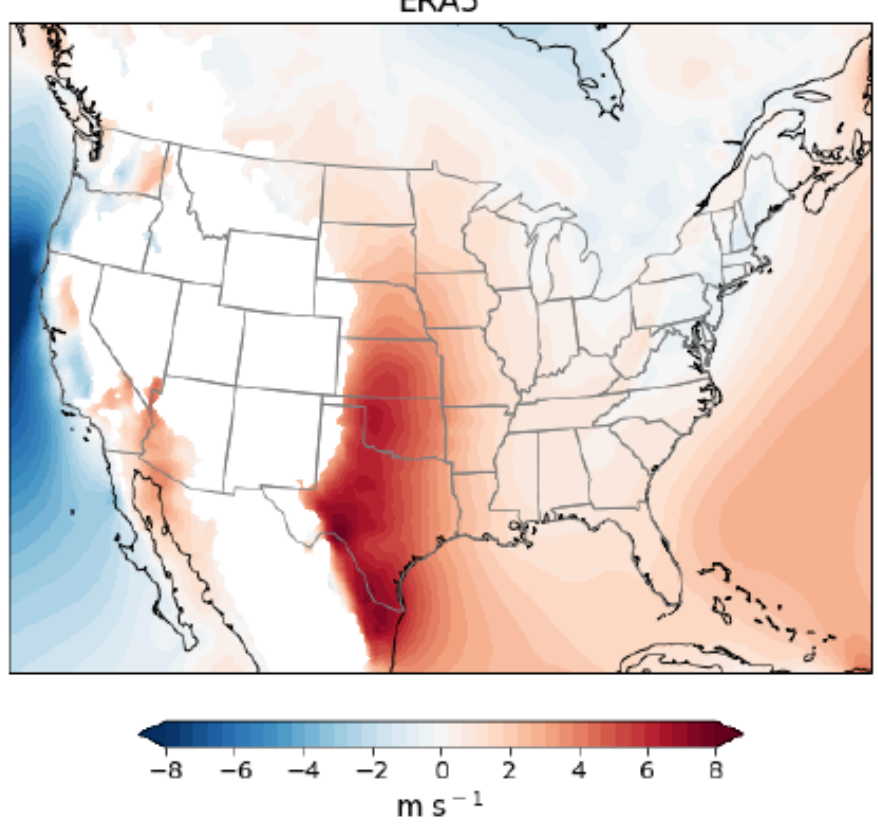

CTRL

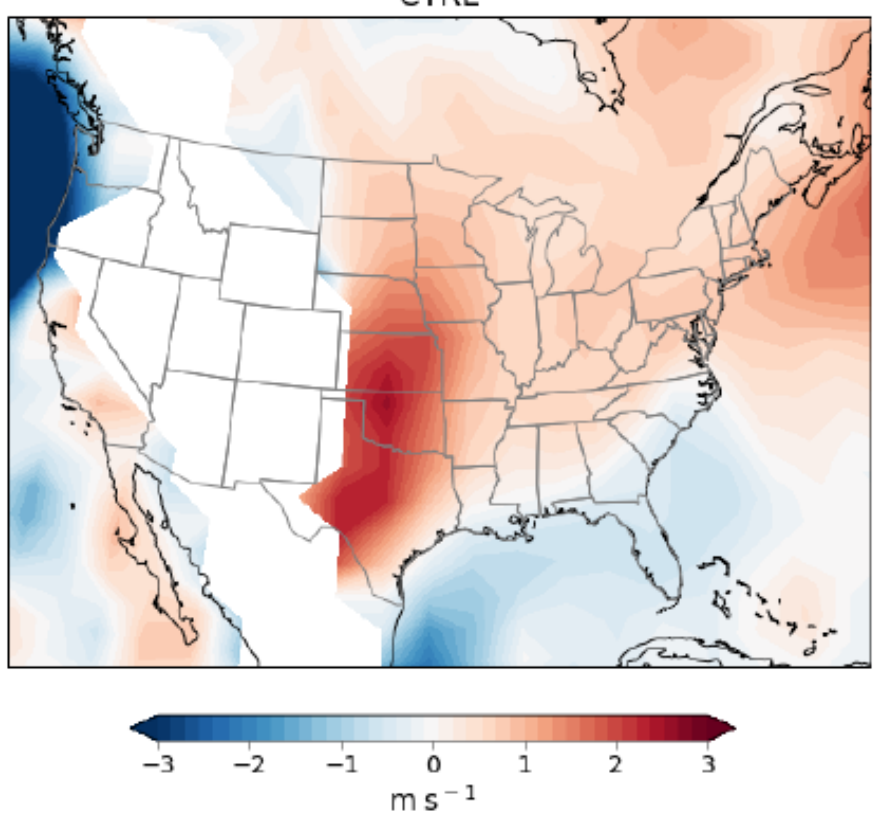

Figure 5

V900 climatology for (left) ERA5 and (right) CTRL experiment. 


\section{Standard deviation of 90-day $\Delta$ V900 moving mean}
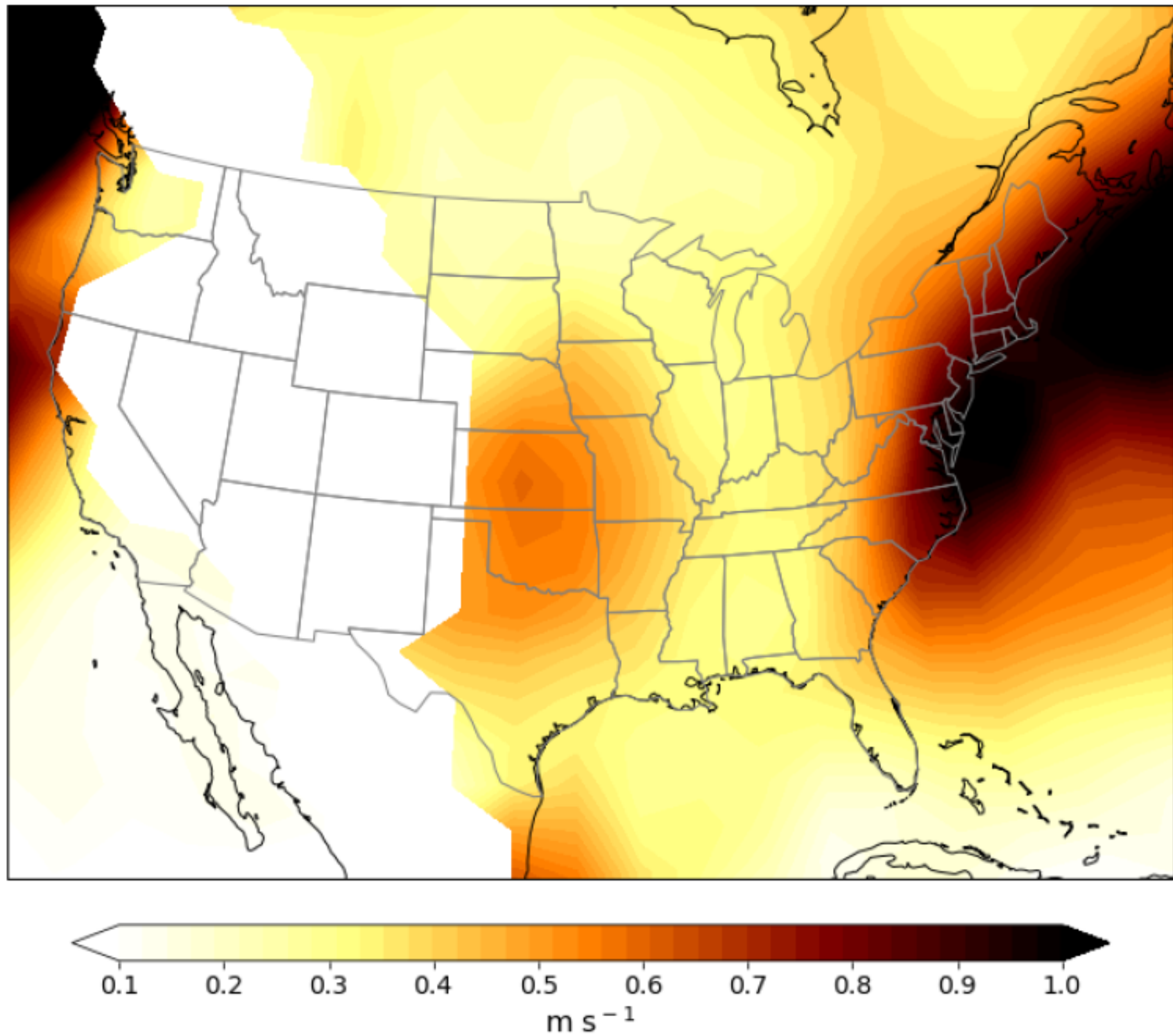

Figure 6

Standard deviation of the 90 -day $\Delta \mathrm{V} 900$ ( $\Delta$ = strong EAM experiment - weak EAM experiment) moving mean. 

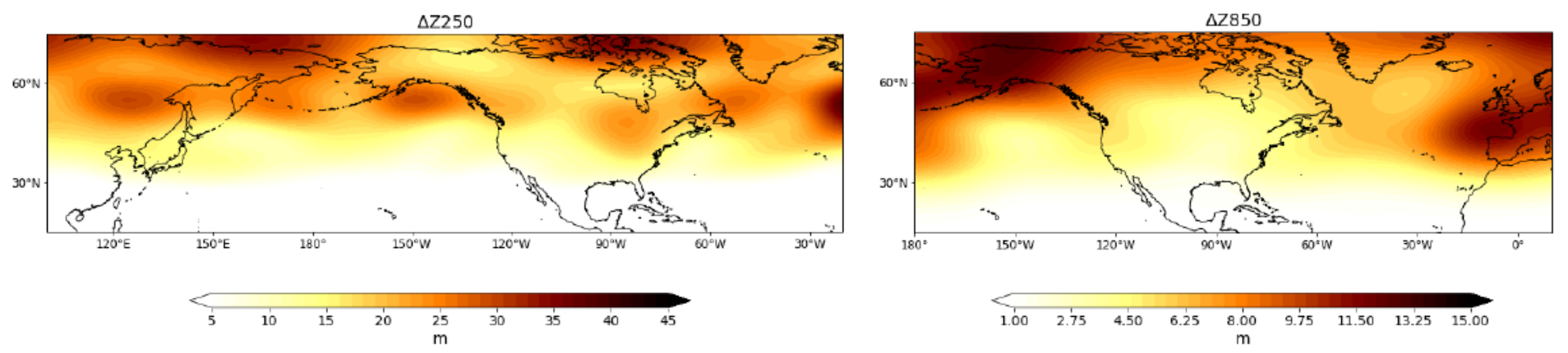

Figure 7

Standard deviation of the 90 -day (left) $\Delta Z 250$ and (right) $\Delta Z 850$ moving mean.

\section{Figure 8}

Time-mean V900 climatology for (left) strong EAM experiment and (middle) weak EAM experiment. (bottom left) Subtraction difference between strong EAM experiment and weak EAM experiment timemean V900, with the $1 \sigma$ (solid black) and $-1 \sigma$ (dashed black) contours overlaid by dividing difference by the standard deviation of the 90 -day $\Delta \mathrm{V} 900$ moving mean.

\section{Figure 9}

Subtraction difference between strong EAM experiment and weak EAM experiment zonally-asymmetric component of the time-mean (left) Z250 and (right) Z850. The $1 \sigma$ (solid black) and $-1 \sigma$ (dashed black) contours are overlaid as in Fig. 7.

\section{Figure 10}

Subtraction difference between strong EAM experiment and weak EAM experiment $35-45^{\circ} \mathrm{N}$ meridionally averaged time-mean profile of (left) $\vee$ and (right) divergence. The $1 \sigma$ (solid black) and $-1 \sigma$ (dashed black) contours are overlaid as in Fig. 7. 


\section{Figure 11}

Modulation of EAM response by NASH: (top row) Subtraction difference between ERA5 strong - weak EAM composites during strong western NASH and weak western NASH, i.e. Fig. 2 bottom row - middle row. (bottom row) Subtraction difference between strong EAM experiment - weak EAM experiment, i.e. strong - weak EAM response during strong western NASH minus strong - weak EAM response during weak western NASH, with 500-250-hPa layer-averaged divergence anomalies instead of precipitation anomalies. Strong - weak EAM V900 anomalies without NASH condition in Great Plains LLJ region are overlaid in left column for reference.

\section{Figure 12}

Modulation of vertical profile of EAM response by NASH: (top) Subtraction difference between ERA5 strong - weak EAM $30^{\circ} \mathrm{N}$ V composites during strong western NASH and weak western NASH. (bottom) Subtraction difference between strong EAM experiment - weak EAM experiment, i.e. strong weak EAM $40^{\circ} \mathrm{N} V$ response during strong western NASH minus strong - weak EAM $40^{\circ} \mathrm{N} V$ response during weak western NASH. Each panel annotates the approximate location of the Great Plains LLJ, and a thin vertical dotted line from LLJ is displayed to visualize upper-level support.

\section{Supplementary Files}

This is a list of supplementary files associated with this preprint. Click to download. 
- MalloyKirtman2021EAMNASHnonlinearmodelsuppmatv3.docx 